\title{
New vaccine strategies against enterotoxigenic Escherichia coli. I: DNA vaccines against the CFA/I fimbrial adhesin
}

A.M.B. Alves ${ }^{1,2}$, M.O. Lásaro ${ }^{1}$,

D.F. Almeida ${ }^{1}$ and L.C.S. Ferreira ${ }^{1}$

\author{
${ }^{1}$ Laboratório de Fisiologia Celular, Instituto de Biofísica Carlos Chagas Filho, \\ Universidade Federal do Rio de Janeiro, Rio de Janeiro, RJ, Brasil \\ ${ }^{2}$ Laboratório de Tecnologia Bacteriana, Bio-Manguinhos, Fundação O swaldo Cruz, \\ Rio de Janeiro, RJ, Brasil
}

\section{Correspondence \\ L.C.S. Ferreira \\ Laboratório de Fisiologia Celular IB, UFRJ \\ 21949-900 Rio de Janeiro, RJ \\ Brasil \\ Fax: + 55-21-280-8193 \\ E-mail: Ics@@ biof.ufrj.br}

Presented at the International Symposium "The Third Revolution on Vaccines: DNA Vaccines", Belo Horizonte, MG, Brasil,

November 3-7, 1997.

Research supported by PADCT, CNPq, PRONEX, CAPES, FAPERJ and FINEP.

Received October 15, 1998

Accepted November 3, 1998

\section{Abstract}

Stimulation of the mammalian immune system by administration of plasmid DNA has been shown to be an important approach for vaccine development against several pathogens. In the present study we investigated the use of DNA vaccines to induce immune responses against an enteric bacterial pathogen, enterotoxigenic Escherichia coli (ETEC). Three plasmid vectors encoding colonization factor antigen I (CFA/I), an ETEC fimbrial adhesin, were constructed. Eukaryotic cells transfected with each of these plasmids expressed the heterologous antigen in different compartments: bound to the cytoplasmic membrane (pRECFA), accumulated in the cytoplasm (pPolyCFA) or secreted to the outside medium (pBLCFA). BALB/c mice were intramuscularly ( $\mathrm{im}$ ) inoculated with purified plasmid DNA and the systemic, cellular and secreted CFA/I-specific immune responses were analyzed. The results showed that all three DNA vaccine formulations could elicit CFA/I-specific immune responses. Moreover, cellular location of the plasmid-encoded CFA/I seems to have an important role in the induced immune response. Taken together, these results indicate that DNA vaccines also represent a promising approach against enteric bacterial pathogens.

\section{Introduction}

Injection of naked DNA encoding specific antigens has been acknowledged as an efficient procedure to present antigens to the mammalian immune system, leading to strong humoral and cellular immune responses (1). DNA vaccines also represent a useful technique to study the antibody responses against a large number of virus-, parasite- and bacterium-derived antigens (2-6). Nonetheless, development of DNA vaccines against enteric bacterial pathogens has not been reported. Enterotoxigenic Escherichia coli (ETEC) is an important cause of diarrhea in children in developing countries and travelers visiting such areas (7). In fact, this pathogen has been recently identified by the World Health Organization (WHO) as one of the target enteric pathogens to be controlled by vaccination (8). Essential virulence factors in ETEC pathogenesis include production of 
enterotoxins and colonization factor antigens (CFAs), which allow the bacteria to attach to and colonize the apical surface of the small intestine epithelial cells (9). CFA/ I is one of the most frequently found CFAs in epidemiological studies and also one of the best characterized at the molecular level. It presents a rigid fimbrial structure composed of several copies of a single protein subunit of $15 \mathrm{kDa}$, endowed with both structural and adhesive roles (10).

In this work we cloned the CFA/I-encoding gene, $c f a B$, in three distinct plasmids under the control of eukaryotic cell promoters. Each plasmid drove the expression of the recombinant CFA/I to different compart-

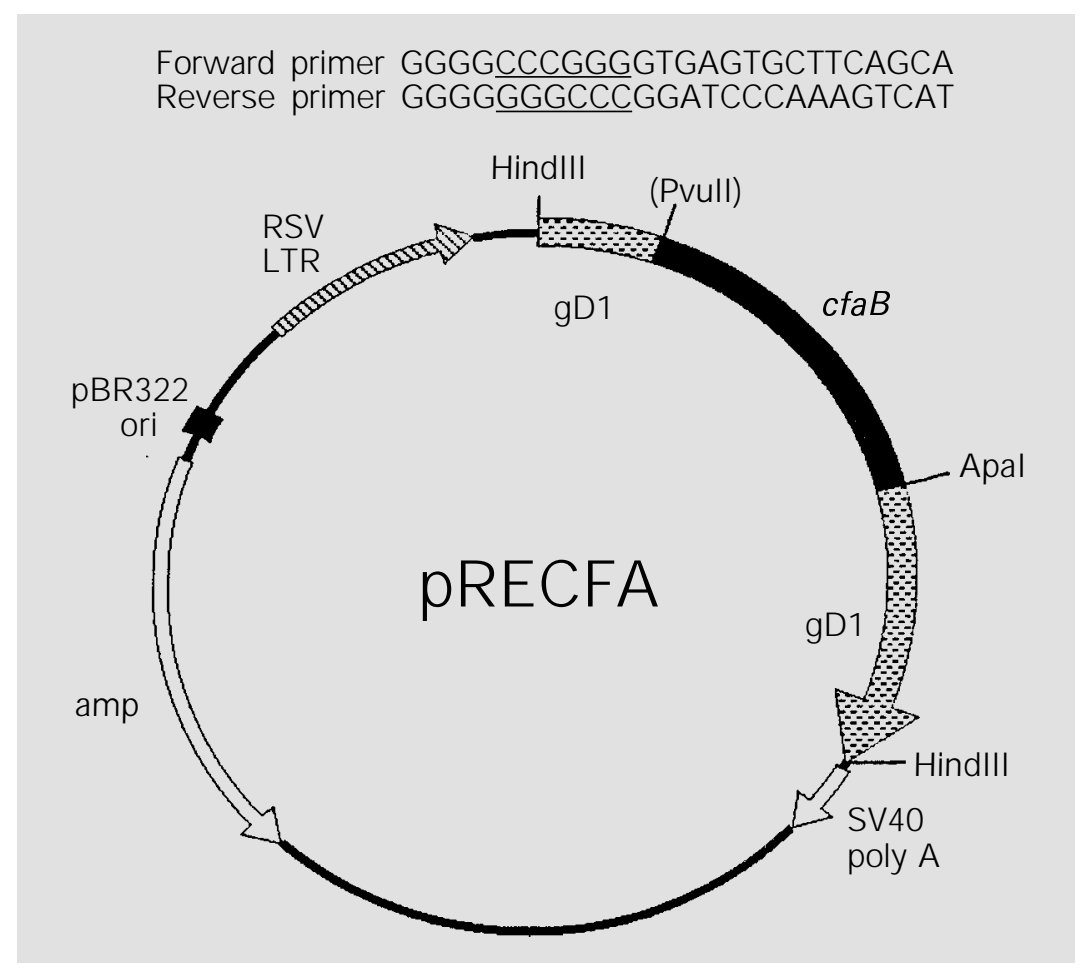

Figure 1 - Schematic representation of pRECFA. Forward and reverse primers containing restriction sites (underlined sequences) for Smal and Apal, respectively, were used to amplify a synthetic gene encoding the mature CFA/l subunit (cfaB). The pRE4 was digested with Pvull and Apal restriction enzymes and the internal 650-bp fragment of the HSV gD1encoding gene was removed. The cfaB gene, obtained after cleavage of the PCR-generated fragment with Smal and Apal, was then cloned in frame with the remaining HSV gD1encoding gene. The original Pvull site of pRE4 was lost during the construction of the recombinant plasmid (marked by brackets). The encoded hybrid protein contained the signal peptide, the first $27 \mathrm{~N}$-terminal and the last $71 \mathrm{C}$-terminal amino acids of the HSV gD1 protein besides the complete amino acid sequence of the CFA/l subunit (147 amino acids). RSV, Rous sarcoma virus; LTR, long terminal repeats. ments of transfected cells and could induce CFA/I-specific immune responses. The results showed that DNA vaccines can also be used to engender immune responses against antigens derived from enteric bacterial pathogens and represent, therefore, a potential vaccine approach against ETEC-associated diarrhea.

\section{Material and Methods}

\section{Plasmids, bacterial strains and culture conditions}

Three eukaryotic cell expression vectors were used to clone the $c f a B$ gene of ETEC. pRE4 was kindly supplied by Dr. G. Cohen (Pennsylvania University, Philadelphia, PA, USA); pkCMVintBL and pkCMVintPoly were obtained from Vical (Vical Inc., San Diego, CA, USA). The ETEC strain 4011-1 (CFA/I, O153:H45, ST) was isolated from a diarrheic child in São Paulo, Brazil, and used as the source of the $c f a B$ gene (11). ETEC strains 258909-3 (CFA/I, O128:H?, ST/LT) and the corresponding CFA/I-negative mutant 258909-3M (12) were used in assays of hemagglutination inhibition. Plasmid amplifications were carried out with the $E$. coli CS1 strain grown in LB medium at $37^{\circ} \mathrm{C}$ under aeration.

\section{Plasmid constructions}

A PCR-amplified fragment containing the $c f a B$ gene was digested with $S m a \mathrm{I}$ and $A p a \mathrm{I}$ and ligated to the larger fragment of $P v u \mathrm{II}-$ ApaI double-digested pRE4 (Figure 1). Recombinant plasmids were confirmed by restricion endonuclease mapping and DNA sequencing. One recombinant plasmid, pRECFA, encoded the CFA/I protein fused with the glycoprotein $\mathrm{D}$ from herpes simplex virus type 1 (HSV gD1) under the control of the Rous sarcoma virus (RSV) promoter (13). The signal sequence and hydrophobic transmembrane stretch of HSV gD1 (14) served 
to target the hybrid gene product to the cytoplasmic membrane of transfected cells (13). pBLCFA was constructed following ligation of a $c f a B$-containing PCR fragment with the larger fragment of BamHI/BglII double-digested pKCMVintBL (Figure 2). Recombinants were confirmed by restriction endonuclease mapping and DNA sequencing. One recombinant plasmid, $\mathrm{pBLCFA}$, containing the $c f a B$ gene fused to the human tissue plasminogen activator (TPA) signal sequence (15) under the control of the human cytomegalovirus (CMV) immediate-early promoter was selected for further study. The TPA signal sequence targeted the hybrid CFA/I protein to the extracellular space of transfected eukaryotic cells (data to be published elsewhere). The third recombinant plasmid, pPolyCFA, was obtained after cloning the $c f a B$ gene into the polylinker site of pkCMVintPoly, using the same cloning strategy as used for pBLCFA construction (Figure 3). pPolyCFA also expressed the $c f a B$ gene under control of the CMV immediateearly promoter but the protein was targeted to the cytoplasm of mammalian cells (data to be published elsewhere). The recombinant plasmids were purified by two equilibrium density $\mathrm{CsCl}$ gradient centrifugations, sterilized by ethanol purification, suspended in sterile phosphate-buffered saline (PBS) and stored at $-20^{\circ} \mathrm{C}$ until use. DNA concentrations were determined at A260 nm and by visual inspection of ethidium bromidestained agarose gels using DNA fragments of known concentration.

\section{Immunization protocol and analysis of the immune responses}

Four to 6-week-old male BALB/c mice were injected $\mathrm{im}$ in each hind limb tibialis anterior muscle with $50 \mu \mathrm{g}$ of plasmid DNA dissolved in $50 \mu \mathrm{l}$ of PBS $(100 \mu \mathrm{g}$ per mouse $)$ using 27-gauge needles. Immunizations were repeated 2 weeks later using the same dose and inoculation procedure. Mice were bled by retro-orbital puncture before and 2 weeks after the second immunization. Secreted IgA responses were evaluated in fecal extracts and small intestinal homogenates, as previously described (16). Enzyme-linked immunosorbent assays (ELISA) with heat-denatured CFA/I subunits as solid-phase bound antigen were used to analyze sera, fecal extracts or intestinal homogenates of immunized mice. MaxiSorp plates (Nunc) were coated with $0.1 \mu \mathrm{g}$ of $\mathrm{CFA} / \mathrm{I}$ suspended in PBS for $1 \mathrm{~h}$ at $37^{\circ} \mathrm{C}$, and blocked overnight with $2 \%(\mathrm{w} / \mathrm{v})$ skim milk in PBS-0.05\% Tween 20 (PBS-T), and reacted with serial dilutions of sera or extracts for $1 \mathrm{~h}$ at $37^{\circ} \mathrm{C}$. Diluted rabbit anti-mouse IgG or IgA-horseradish peroxidase conjugates (Sigma), used

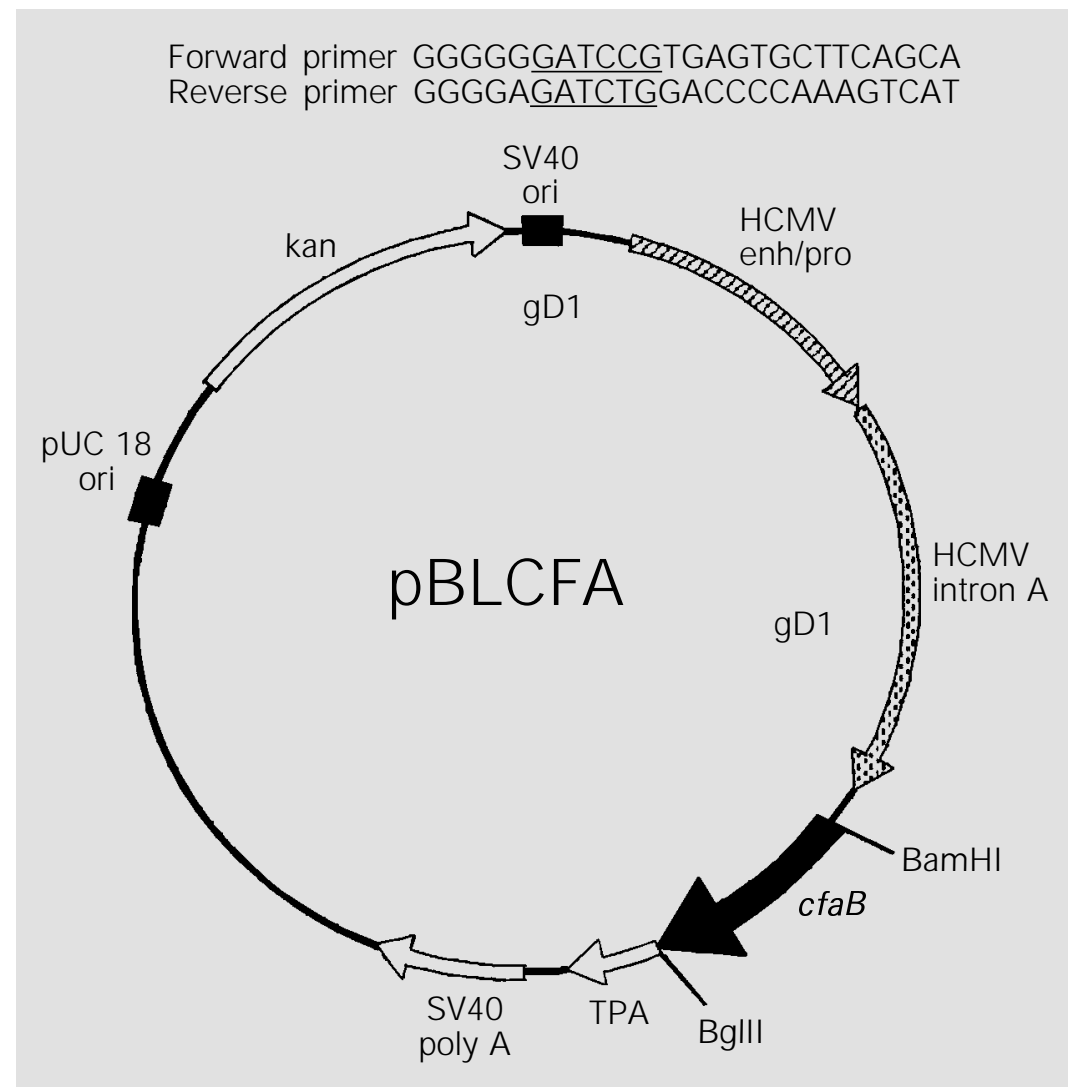

Figure 2 - Schematic representation of pBLCFA. Forward and reverse primers containing restriction sites (underlined sequences) for BamHI and Bglll, respectively, were used to amplify a synthetic gene encoding the mature CFA/l subunit (cfaB). The pKCMVintBL was digested with such enzymes, as also was the PCR-generated cfaB gene fragment. The $\mathrm{cfaB}$ gene was then cloned in the PKCMVintBL upstream of the tissue plasminogen activator (TPA) signal sequence, which served to target CFA/l to the extracellular space. HCMV, Human cytomegalovirus. 
as secondary antibodies, were added to the wells and incubated for $1 \mathrm{~h}$ at $37^{\circ} \mathrm{C}$. The reactions were developed with ortho-phenylenediamine hydrochloride (Sigma) and $\mathrm{H}_{2} \mathrm{O}_{2}$ as substrate. Delayed-type hypersensitivity (DTH) responses were detected in mice injected in the right and left footpad with 10 $\mu \mathrm{g}$ of the CFA/I protein and PBS, respectively. The thickness of each footpad was measured 24 and $48 \mathrm{~h}$ after injection. Mice were then sacrificed and draining lymph nodes (pulpliteo) withdrawn and weighed on an analytical balance.

\section{Inhibition of hemagglutination assays}

Inhibition of hemagglutination (IHA) assays were carried out with ETEC cells (strains

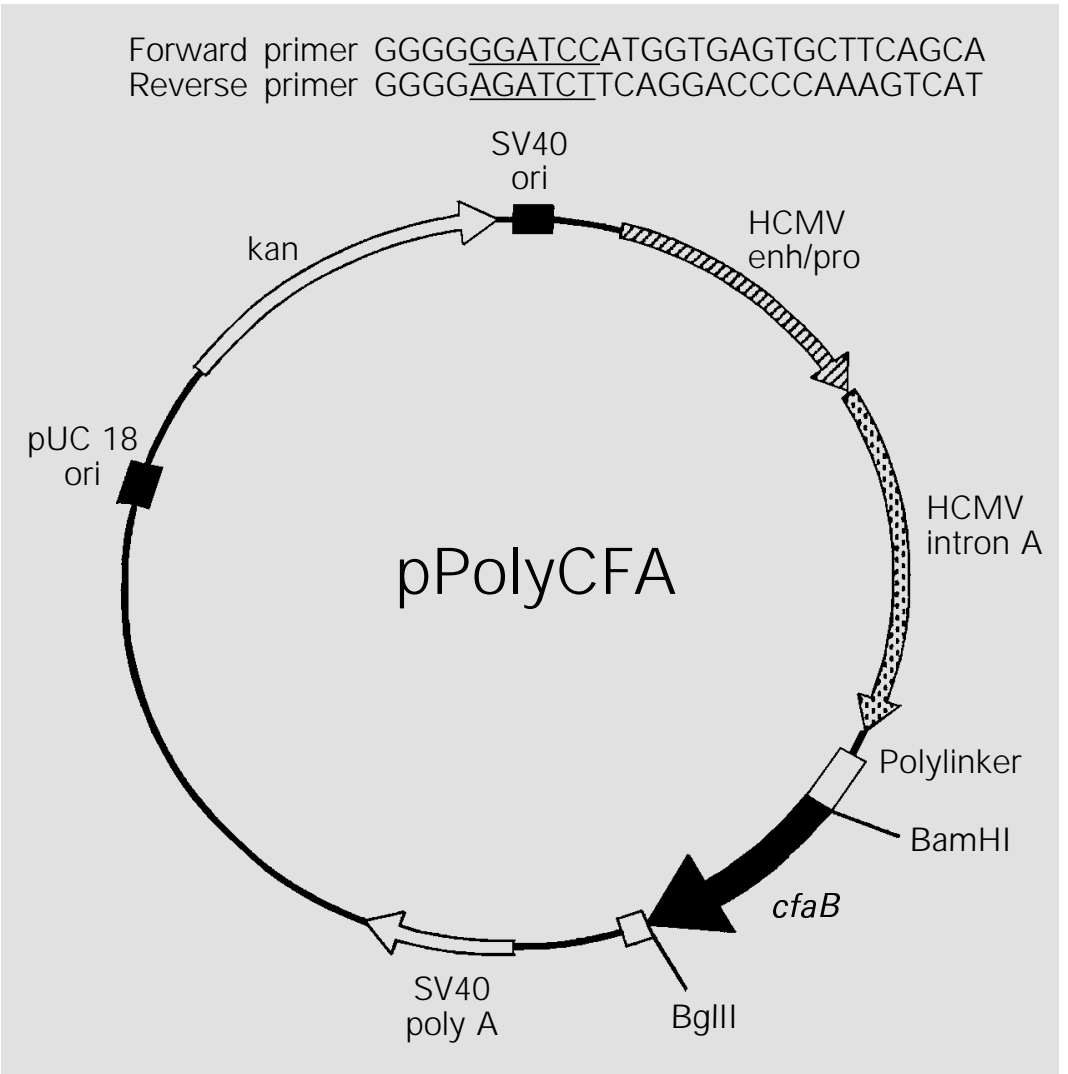

Figure 3 - Schematic representation of pPolyCFA. Forward and reverse primers containing restriction sites (underlined sequences) for BamHI and Bglll, respectively, were used to amplify a synthetic gene encoding the mature CFA/l subunit (cfaB). pkCMVintPoly was digested with such enzymes, as well as the PCR-generated cfaB gene fragment. The resulting $\mathrm{cfaB}$ gene was cloned in the pkCMVintPoly polylinker region. HCMV, Human cytomegalovirus.
258909-3 or 258909-3M) suspended in PBS containing $0.5 \%$ D-mannose and human group A erythrocytes (2\%), as previously described (13). Sera from DNA-vaccinated mice were incubated with the indicator ETEC strains for $10 \mathrm{~min}$ at room temperature before addition of the red blood cells. Sera from mice immunized with purified CFA/I fimbriae were used as a positive control.

\section{Results and Discussion}

A summary of the CFA/I-specific immune responses elicited in BALB/c mice immunized with pRECFA, pBLCFA or pPolyCFA is presented in Table 1. Mice injected with one or two $100-\mu \mathrm{g}$ doses of pRECFA developed a homogeneous and reproducible serum antibody response against the CFA/I subunit. The CFA/I-specific IgG titers attained maximal values (average of $\log _{10} 3.5$ in mice immunized once and $\log _{10}$ 4.05 in mice immunized with two doses) between 2 and 4 weeks after DNA injection. Nonetheless, sera from mice immunized with pRECFA did not inhibit the adhesive properties of intact CFA/I fimbriae expressed on ETEC cells, as evaluated in IHA assays. Therefore, epitope specificity of pRECFAinduced CFA/I-specific antibodies does not afford appropriate recognition of the fimbrial adhesive domain. Since there is a good correlation between the IHA test and the ability of CFA/I-expressing ETEC cells to bind human enterocyte receptors, the pRECFA-induced antibodies may not be effective against gut colonization by $\mathrm{CFA} / \mathrm{I}^{+}-$ ETEC cells. The epitope specificity of pRECFA-induced antibodies probably reflects the structure of the recombinant hybrid protein expressed by transfected cells. Under such new conformation (membrane bound and fused to HSV gD1 protein), conformational epitopes found on the native protein would be lost and only linear epitopes would be available for the generation of CFA/I-specific antibodies. In accordance 
with this hypothesis, pRECFA-induced antibodies recognized denatured ETEC fimbriae, such as CS1, CS4, and PCFO166, sharing significant amino acid homologies with CFA/ $\mathrm{I}$ in regions which are not exposed on the surface of intact fimbriae (13).

Mice inoculated with pBLCFA presented a heterogeneous serum antibody response. Those immunized once showed low CFA/Ispecific antibody levels (titer of $\log _{10} 2$, average of positive animals) but a second DNA dose elicited a systemic CFA/I-specific antibody response in most animals, although with a rather larger titer range (average of $\log _{10} 5.2 \pm 2$ in IgG-ELISA) (data not shown). Similar results were also observed with other DNA vaccines, in which more than one dose was required for full induction of an antibody response, probably due to the reduced number of transfected cells $(2,4,5)$. In contrast to the antibodies induced by pRECFA, serum antibodies raised against pBLCFAencoded CFA/I inhibited the binding properties of intact CFA/I fimbriae (Table 1). Such results suggest that conformational epitopes similar to those found on native CFA/I fimbriae were preserved on the recombinant CFA/I protein encoded by pBLCFA. Supposedly the secretion of CFA/I subunits into the surrounding medium can restore at least part of the conformation and, therefore, epitopes of intact fimbriae expressed by bacterial cells.

Mice immunized with pPolyCFA were not able to elicit a systemic CFA/I-specific antibody response. None of the animals inoculated with one or two DNA doses developed antibody responses against intact or dissociated CFA/I fimbriae (Table 1). The in vitro expression of $\mathrm{CFA} / \mathrm{I}$ protein by pPolyCFA-transfected mammalian cells revealed that the recombinant protein is accumulated intracellularly (data not shown). Thus, the intracellular location of pPolyCFAencoded CFA/I does not seem to contribute to an efficient activation of antibody-producing cells.
All three CFA/I-encoding vectors were proficient in the activation of the cellular immune response in vaccinated mice, as evaluated in DTH tests. Lymph nodes withdrawn from all immunized mice were three to four times heavier than those removed from limbs injected with PBS. Taken together, these observations demonstrate that systemic and cellular immune responses induced by DNA vaccines encoding the same antigen may differ according to the expression vector used. Production of a specific antibody response induced by DNA immunization, in contrast to the cellular response evaluated by DTH, seems to depend on the cellular location of the encoded antigen. It seems that, at least in the case of the vectors used to express CFA/I, the encoded protein should become available to antigen-presenting cells either anchored to the cytoplasmic membrane (as the recombinant protein encoded by pRECFA), or secreted into the extracellular environment (as the antigen encoded by pBLCFA). The present results support previous observations that immunization with plasmid DNA encoding intracellularly located proteins does not efficiently promote antigen-specific antibody responses $(17,18)$. In fact most DNA vaccines which

Table 1 - Immune stimulatory properties of the three CFA/l-encoding plas mids following im inoculation in BALB/C mice.

aEvaluated in IgG-ELISA using denatured CFA/I subunits as solid-phase bound antigen. ${ }^{b}$ Evaluated by the ability to block the hemagglutination properties of CFA/l fimbriae expressed by ETEC strain 258909-3 (CFA/I, O128:H?, ST/LT). CEvaluated by footpad swelling or lymph node weights of mice immunized with the DNA vaccines and tested with purified CFA/I protein. dPresence of IgA determined in CFA/I-specific IgA-ELISA using fecal extracts and small intestine homogenates. DTH, Delayed-type hypersensitivity responses.

\begin{tabular}{lcccc}
\hline Vectors & & Humoral response & $\begin{array}{c}\text { Cellular } \\
\text { response }\end{array}$ & $\begin{array}{r}\text { Mucosal } \\
\text { response }\end{array}$ \\
\cline { 2 - 5 } & $\begin{array}{c}\text { Antibody } \\
\text { production }^{\mathrm{a}}\end{array}$ & $\begin{array}{c}\text { Inhibition of } \\
\text { hemagglutination }\end{array}$ & DTH $^{\mathrm{c}}$ & $\begin{array}{c}\text { slgA } \\
\text { production }^{\mathrm{d}}\end{array}$ \\
\hline pRECFA & + & - & + & - \\
pBLCFA & + & + & + & - \\
pPolyCFA & - & - & + & -
\end{tabular}


engendered good antibody responses seemed to encode surface-located or secreted antigens $(2,19-21)$, although exceptions can occur $(1,22)$.

None of the vectors tested was able to induce CFA/I-specific IgA responses in the gut mucosa or in fecal extracts from vaccinated mice (Table 1). It is well known that an effective immunization against an enteric bacterial pathogen such as ETEC requires the induction and secretion of mucosal antibodies (sIgA) (9); thus, parenteral inoculation of DNA vaccines does not seem to represent an appropriate route for the induction of mucosal sIgA responses. Alternative inoculation routes such as oral delivery of live attenuated Shigella or Salmonella strains carrying DNA vaccine plasmid vectors seem to represent promising alternatives to stimu- late the mucosal immune system $(23,24)$. Moreover, recent observations indicate that coadministration of purified plasmids expressing specific cytokines can help to stimulate sIgA production against antigens encoded by DNA vaccines (25). Therefore, testing alternative inoculation routes or immunization strategies would be of interest to fully evaluate the efficacy of DNA vaccines against ETEC.

\section{Acknowledgments}

We acknowledge the invaluable technical assistance of Celso Pereira and Eduardo Camacho. We also thank Dr. G. Cohen and Robert Zaug for supplying the expression vectors used to clone the $c f a B$ gene.

\section{References}

1. Ulmer J B, Donnelly J J, Parker SE, Rhodes GH, Felgner PL, Dwarki VJ , Gromkowski $\mathrm{SH}$, Deck RR, DeWitt CM, Friedman A, Hawe LA, Leander KR, Martinez D, Perry HC, Shiver J W, Montgomery DL \& Liu MA (1993). Heterologous protection against influenza by injection of DNA encoding a viral protein. Science, 259: 17451749.

2. Xiang ZQ, Spitalnik SL, Tran M, Wunner WH, Cheng J \& Ertl HCJ (1994). Vaccination with a plasmid vector carying the rabies virus glycoprotein gene induces protective immunity against rabies virus. Virology, 199: 132-140.

3. Davis HL, McCluskie MJ, Gerin JL \& Purcell RH (1996). DNA vaccine for hepatitis B: Evidence for immunogenicity in chimpanzees and comparison with other vaccines. Proceedings of the National Academy of Sciences, USA, 93: 72137218.

4. Sedegah $M$, Hedstrom $R$, Hobart $P \&$ Hoffman SL (1994). Protection against malaria by immunization with plasmid DNA encoding circumsporozoite protein. Proceedings of the National Academy of Sciences, USA, 91: 9866-9870.

5. Anderson R, Gao XM, Papakonstantinopoulou A, Roberts $M$ \& Dougan $G$ (1996). Immune response in mice follow- ing immunization with DNA encoding fragment $\mathrm{C}$ of tetanus toxin. Infection and Immunity, 64: 3168-3173.

6. Huygen K, Content J, Denis O, Montgomery DL, Yawman AM, Deck RR, DeWitt $C M$, Orme IM, Baldwin S, D'Souza C, Drowart A, Lozes $E$, Vandenbussche $P$, Van Vooren JP, Liu MA \& Ulmer J B (1996). Immunogenicity and protective efficacy of a tuberculosis DNA vaccine. Nature Medicine, 2: 893-898.

7. Black RE (1993). Epidemiology of diarrheal disease: implications for control by vaccines. Vaccine, 11: 100-106.

8. Sansonetti PJ (1998). Slaying the Hydra all at once or head by head? New candidate vaccines show promise in protecting against the diverse pathogens that cause diarrheal diseases. Nature Medicine, 4: 499-500.

9. Levine MM (1987). Escherichia coli that cause diarrhea: enterotoxigenic, enteropathogenic, enteroinvasive, enterohemorrhagic and enteroadherent. J ournal of Infectious Diseases, 155: 377-389.

10. Evans DG, Evans J r DJ , Clegg S \& Pauley J A (1979). Purification and characterization of the CFA/l antigen of enterotoxigenic Escherichia coli. Infection and Immunity, 25: 738-748.

11. Guth BEC, Pacheco ABF, von Krüger
WMA \& Ferreira LCS (1995). Comparison of outer membrane protein and lipopolysaccharide profile of enterotoxigenic Escherichia coli strains isolated in São Paulo, Brazil. Brazilian J ournal of Medical and Biological Research, 28: 545-551.

12. Gothefors L, Ahren C, Stoll B, Barua DK, Orskov F, Salek MA \& Svennerholm A-M (1985). Presence of colonization factor antigens on fresh isolates of fecal Escherichia coli: a prospective study. J oumal of Infectious Diseases, 152: 1128-1133.

13. Alves AMB, Lásaro MO, Almeida DF \& Ferreira LCS (1998). Epitope specificity of antibodies raised against enterotoxigenic Escherichia coli CFA/l fimbriae in mice immunized with naked DNA. Vaccine, 16: 9-15.

14. Watson RJ, Weis JH, Salstrom JS \& Enquist LW (1982). Herpes simplex virus type-1 glycoprotein $D$ gene: nucleotide sequence and expression in Escherichia coli. Science, 218: 381-383.

15. Chapman BS, Thayer RM, Vincent KA \& Haigwood NL (1991). Effect of intron A from human cytomegalovirus (Towne) immediate-early gene on heterologous expression in mammalian cells. Nucleic Acids Research, 19: 3979-3986.

16. Guillobel HCR, Luna MG, Camacho EF, Almeida DF \& Ferreira LCS (1998). Immu- 
nization against the colonization factor antigen I of enterotoxigenic Escherichia coli by administration of a bivalent Salmonella typhimurium aroA strain. Brazilian J oumal of Medical and Biological Research, 31: 545-554.

17. Yokoyama M, Zhang \& \& Whitton L (1995) DNA immunization confers protection against lethal lymphocytic choriomeningitis virus infection. J oumal of Virology, 69: 2684-2688.

18. Martins LP, Lau LL, Asano MS \& Ahmed $R$ (1995). DNA vaccination against persistent viral infection. J oumal of Virology, 69: 2574-2582.

19. Fynan EF, Webster RG, Fuller DH, Haynes J R, Santoro JC \& Robinson HL (1993). DNA vaccines: Protective immunizations by parenteral, mucosal, and gene-gun inoculations. Proceedings of the National
Academy of Sciences, USA, 90: 1147811482.

20. Robinson HL, Hunt LA \& Webster RG (1993). Protection against a lethal influenza virus challenge by immunization with a haemagglutinin-expressing plasmid DNA. Vaccine, 11: 957-960.

21. Davis HL, Mancini $M$, Michel $M L \&$ Whalen RG (1996). DNA-mediated immunization to hepatitis B surface antigen: longevity of primary response and effect of boost. Vaccine, 14: 910-915.

22. Yankauckas MA, Morrow J E, Parker SE, Abai A, Rhodes GH, Dwarki VJ \& Gromkowski SH (1993). Long-term antinucleoprotein cellular and humoral immunity is induced by intramuscular injection of plasmid DNA containing NP gene. DNA and Cell Biology, 12: 771-776.

23. Sizemore DR, Branstrom AA \& Sadoff J C
(1995). Attenuated shigella as a DNA delivery vehicle for DNA-mediated immunization. Science, 270: 299-302.

24. Darji A, Guzmán CA, Gerstel B, Wachholz $P$, Timmis KN, Wehland J , Chakraborty T $\&$ Weiss S (1997). Oral somatic transgene vaccination using attenuated $\mathrm{S}$. typhimurium. Cell, 91: 765-775.

25. Okada E, Sasaki S, Ishii N, Aoki I, Yasuda T, Nishioka K, Fukushima J, Miyazaki J I, Wahren B \& Okuda K (1997). Intranasal immunization of a DNA vaccine with IL12- and granulocyte-macrophage colonystimulating factor (GM-CSF)-expressing plasmids in liposome induces strong mucosal and cell-mediated immune responses against HIV-1 antigens. Journal of Immunology, 159: 3638-3647. 